\title{
PI3K inhibition as a novel therapeutic strategy for neoadjuvant chemoradiotherapy resistant oesophageal adenocarcinoma
}

Running title: PI3K signalling as a therapeutic target in radioresistant OAC

Full paper submission

Sarah D. Edge ${ }^{1}$, Isaline Renard ${ }^{2}$, Emily Pyne ${ }^{1}$, Hannah Moody ${ }^{1,3}$, Rajarshi Roy ${ }^{4}$, Andrew W. Beavis $5,6,7$, Stephen J. Archibald ${ }^{2}$, Christopher J. Cawthorne ${ }^{2,9, *}$, Stephen G. Maher ${ }^{10, *}$, Isabel M. Pires ${ }^{1, *}$

${ }^{1}$ Hypoxia and Tumour Microenvironment Lab, Department of Biomedical Sciences, Faculty of Health Sciences, University of Hull, UK

${ }^{2}$ Positron Emission Tomography Centre, Department of Biomedical Sciences, Faculty of Health Sciences, University of Hull, UK

${ }^{3}$ Present address: Institute of Cancer Therapeutics; School of Medicine and Medical Sciences, University of Bradford, UK

${ }^{4}$ Queen's Centre for Oncology and Haematology, Castle Hill Hospital, Castle Rd, Cottingham HU16 5JQ, UK

${ }^{5}$ Department of Medical Physics, Queen's Centre for Oncology, Hull University Teaching Hospitals NHS Trust, Cottingham, HU16 5JQ, UK

${ }^{6}$ Faculty of Health Sciences, University of Hull, Cottingham road, Hull, HU16 7RX, UK

${ }^{7}$ Faculty of Health and Well Being, Sheffield-Hallam University, Collegiate Crescent, Sheffield, S10 2BP

${ }^{8}$ Department of Surgery, Trinity Translational Medicine Institute, Trinity College Dublin, St. James's Hospital, Dublin, Ireland

${ }^{9}$ Nuclear Medicine and Molecular Imaging, Department of Imaging and Pathology, KU Leuven, 3000 Leuven, Belgium

${ }^{10}$ Department of Surgery, Trinity Translational Medicine Institute, Trinity College Dublin, St. James's Hospital, Dublin, Ireland

\section{* Co-corresponding authors:}

- Isabel M. Pires - i.pires@hull.ac.uk

University of Hull, Department of Biomedical Sciences; Hull, HU6 7RX, UK

- Stephen G. Maher - maherst@tcd.ie

Department of Surgery, Trinity Translational Medicine Institute, Trinity College Dublin, St. James's Hospital; Dublin, Ireland

- Christopher J. Cawthorne - christopher.cawthorne@kuleuven.be

Nuclear Medicine and Molecular Imaging, Department of Imaging and Pathology, KU Leuven; 3000 Leuven, Belgium

Conflicts of interest: The authors declare no conflict of interests. Funding noted below.

Funding: SE, SGM, CJC, EP, and IMP were supported by University of Hull PhD studentships. SE, SGM, and CJC were supported by a Cancer and Polio Research Fund grant. We would also like to thank $\mathrm{Dr}$ Assem Allam and his family for their generous donation to help fund the PET Research Centre at the University of Hull and for funding a PhD scholarship for IR.

Acknowledgements: The authors would like to thank Ellie Beeby and Dr Becky Bibby for technical support.

Keywords: oesophageal cancer, PI3K, miR-187, radiation, PTEN 
bioRxiv preprint doi: https://doi.org/10.1101/2020.10.23.351981; this version posted October 23,2020 . The copyright holder for this preprint (which was not certified by peer review) is the author/funder. All rights reserved. No reuse allowed without permission.

Running title: PI3K signalling as a therapeutic target in radioresistant OAC

\begin{abstract}
Objectives: Neoadjuvant chemo-radiotherapy (neo-CRT) prior to surgery is the standard of care for oesophageal adenocarcinoma (OAC) patients. Unfortunately, most patients fail to respond to treatment. MiR-187 was previously shown to be downregulated in neo-CRT nonresponders, whist in vitro miR-187 overexpression enhanced radio-sensitivity and upregulated PTEN. This study evaluates the role of miR-187 and downstream PI3K signalling in radiation response in OAC.
\end{abstract}

Methods: The effect of miR-187 overexpression on downstream PI3K signalling was evaluated in OAC cell lines by qPCR and western blotting. PTEN expression was analysed in OAC pretreatment biopsies of neo-CRT responders and non-responders. Pharmacological inhibition of PI3K using GDC-0941 was evaluated in combination with radiotherapy in 2D and 3D OAC models in vitro and as a single agent in vivo. Radiation response in vitro was assessed via clonogenic assay.

Results: PTEN expression was significantly decreased in neo-CRT non-responders. MiR-187 overexpression significantly upregulated PTEN expression and inhibited downstream PI3K signalling in vitro. GDC-0941 significantly reduced viability and enhanced radiation response in vitro and led to tumour growth inhibition as a single agent in vivo.

Conclusions: Targeting of PI3K signalling is a promising therapeutic strategy for OAC patients who have repressed miR-187 expression and do not respond to conventional neo-CRT.

Advances in knowledge: This is the first study evaluating the effect of PI3K inhibition on radiosensitivity in OAC, with a particular focus on patients that do not respond to neo-CRT. We have shown for the $1^{\text {st }}$ time that targeting of PI3K signalling is a promising alternative therapeutic strategy for OAC patients who do not respond to conventional neo-CRT. 
bioRxiv preprint doi: https://doi.org/10.1101/2020.10.23.351981; this version posted October 23,2020 . The copyright holder for this preprint (which was not certified by peer review) is the author/funder. All rights reserved. No reuse allowed without permission.

Running title: PI3K signalling as a therapeutic target in radioresistant OAC

\section{Introduction}

Oesophageal cancer has extremely poor prognosis and is the seventh most common and sixth most lethal cancer worldwide (1). Oesophageal adenocarcinoma (OAC) is the most prevalent histological subtype in western countries, with rapidly rising incidence rates $(2) \cdot(3)$. Neoadjuvant chemoradiotherapy (neo-CRT) is becoming the standard of care for patients with locally advanced OAC (4). Patients achieving a pathological complete response (pCR) upon neo-CRT have been shown to have five-year survival rates up to $50 \%$ (5). Unfortunately, less than one third of OAC patients treated with neo-CRT achieve pCR (6). Therefore, identification of predictive therapy response biomarkers and novel therapeutic strategies is essential to improve patient prognosis.

MicroRNAs (miRNAs) are gene expression regulators, identified as predictors and modulators of treatment response in OAC (7). We have previously demonstrated that miR-31, miR-330$5 p$ and miR-187 are significantly downregulated in pre-treatment tumour biopsies from OAC patients who are poor responders to neo-CRT (8-10). MiR-187 overexpression significantly enhanced sensitivity to radiotherapy and cisplatin in vitro and altered gene expression patterns, including PTEN (10). PTEN is a negative regulator of the phosphatidylinositol 3 kinase (PI3K)-protein kinase $\mathrm{B}(\mathrm{AKT})$ signalling pathway, whose hyperactivation is implicated cancer development and progression (11). Activation of PI3K-AKT signalling has been demonstrated in OAC (12), although the potential clinical relevance of PI3K inhibitors remains poorly understood.

GDC-0941 is a potent pan-PI3K inhibitor (13). Pre-clinical studies and phase I clinical trials have demonstrated that GDC-0941 promotes anti-tumorigenic effects and is suitable for treatment of solid tumours (13-16). GDC-0941 was also shown to enhance radio-sensitivity in 
Running title: $\mathrm{PI} 3 \mathrm{~K}$ signalling as a therapeutic target in radioresistant OAC

glioblastoma multiforme in vitro and in thyroid carcinoma in vivo $(17,18)$. However, antitumorigenic properties of GDC-0941 have not previously been assessed in OAC.

In this study, we investigated the role of miR-187 and the PI3K axis in modulating response to neo-CRT. We showed that PTEN expression is downregulated in OAC patients who are poor responders to neo-CRT, and that miR-187 overexpression increases PTEN expression and downregulates $\mathrm{p}$-AKT levels in OAC cells. We then targeted PI3K signalling in OAC cell lines using GDC-0941, which led to decreased cell survival, increased radio-sensitivity in vitro, and inhibition of in vivo tumour growth for the first time in OAC. Taken together, we are demonstrating for the $1^{\text {st }}$ time that targeting $\mathrm{PI} 3 \mathrm{~K}$ in $\mathrm{OAC}$ is a promising therapeutic strategy in OAC and could improve outcome of patients who have repressed miR-187 expression and do not respond to conventional neo-CRT. 
bioRxiv preprint doi: https://doi.org/10.1101/2020.10.23.351981; this version posted October 23,2020 . The copyright holder for this preprint (which was not certified by peer review) is the author/funder. All rights reserved. No reuse allowed without permission.

Running title: PI3K signalling as a therapeutic target in radioresistant OAC

\section{Methods and Materials}

\section{Cell culture, transfections, drug treatments, and irradiation treatment}

OAC OE33, OE19 and SK-GT-4 cell lines were purchased from ECACC (UK). Cells were incubated at $37^{\circ} \mathrm{C}, 95 \%$ humidified air and $5 \% \mathrm{CO}_{2}$. Spheroids were generated by seeding $2.5 \times 10^{4}$ cells per well in ultra-low adherence round-bottomed 96-well plates (Corning). Media was replaced every 2 days. Spheroids were imaged using the GelCount instrument (Oxford Optronix), and spheroid size determined as previously reported $(19,20)$.

Ambion pre-miR miRNA precursor molecules (Thermo Fisher Scientific, UK) were used for transient miR-187 overexpression. GDC-0941 stock solutions (Abcam, UK; Selleckchem, UK) were prepared in DMSO (dimethyl sulfoxide). X-ray irradiation was carried out using a RS2000 biological irradiator (Rad Source Technologies, Georgia, USA) at a $1.87 \mathrm{~Gy} / \mathrm{min}$ dose rate, calibrated to National Physics Laboratory (NPL) standards (21).

\section{Patient treatment, tissue collection, and histology}

Following ethical approval (Joint St James's Hospital/AMNCH ethical review board, Reference ID 2011/27/01) and written informed consent, diagnostic biopsy tumour specimens were taken from patients with a diagnosis of operable OAC, prior to neo-CRT. All patients received a complete course of neo-CRT, consisting of two courses of 5-fluorouracil (5-FU) and cisplatin, plus $40.05 \mathrm{~Gy}$ in 15 daily fractions (2.67 Gy/fraction) over 3 weeks as previously described (22). Diagnostic endoscopic biopsies were obtained prior to neo-CRT. Immediately adjacent tissue was taken for histologic confirmation, which was performed using routine Haematoxylin and Eosin staining. Specimens were immediately placed in RNAlater (Ambion) and refrigerated for $24 \mathrm{~h}$, before removal of RNA later and storage at $-80^{\circ} \mathrm{C}$. 
Running title: PI3K signalling as a therapeutic target in radioresistant OAC

All specimens were assessed by an experienced pathologist. Tumour response to treatment was assigned 1 of 5 tumour regression grades (TRG) as previously described (23). Good responders were classified as achieving a TRG of 1 or 2 , whilst poor responders were classified as having a TRG of 3,4 or 5 , as previously described (9). For the purposes of this study patients with a TRG 3 were excluded.

\section{In vivo studies}

Xenograft models were generated through the subcutaneous implant of $5 \times 10^{6}$ OE33 cells into the right-hand side of the middorsal region of the back of $16 \times 52-58$ day old female CB17.CgPrkdc $^{\text {scid }}$ Lyst $^{\text {bg-J }}$ SCID- Bg mice (sourced from Charles River UK). Animals were anaesthetised using $2 \%$ isoflurane, and a small area of fur shaved around the implant site prior to implant. The cell suspension was prepared in a 1:1 ratio of serum free RPMI medium and Cultrex BME (24), prior to implant of $0.1 \mathrm{~mL}$ of the $5 \times 10^{7}$ cells/ $\mathrm{mL}$ suspension. Tumour measurements were taken three times weekly with callipers and animals randomly assigned to control and treatment groups when tumour volume reached approximately $300-350 \mathrm{~mm}^{3}(14,25,26)$. Three animals developed tumours at a later date and were not included in the analysis of tumour growth. Twice daily treatments of GDC-0941 or vehicle control $(0.1 \mathrm{~mL} / 10 \mathrm{~g})$ were administered via oral gavage at a concentration of $50 \mathrm{mg} / \mathrm{kg}$ for 8 days, as previously reported \{Burrows, 2011 \#23;Burrows, 2013 \#32;Cawthorne, 2013 \#33. Health status and weight of each animal were monitored throughout the experiment. Animals were sacrificed via a schedule 1 method (dislocation of the neck), and tumours were excised and snap frozen. All procedures were carried out in accordance with the Animals (Scientific Procedures) Act 1986 and UKCCCR Guidelines 2010 using protocols approved by the University of Hull Animal Welfare and Ethical Review Body (AWERB) under Home Office Project Licence 60/4549. The 
bioRxiv preprint doi: https://doi.org/10.1101/2020.10.23.351981; this version posted October 23,2020 . The copyright holder for this preprint (which was not certified by peer review) is the author/funder. All rights reserved. No reuse allowed without permission.

Running title: PI3K signalling as a therapeutic target in radioresistant OAC

study was powered using effect sizes and tumour growth variability seen in previous experiments B Burrows, 2011 \#23;Burrows, 2013 \#32;Cawthorne, 2013 \#33 using G*Power software (27). Tumour growth over the entire course of treatment was compared between groups.

\section{RT-qPCR}

Xenograft tumour tissue samples and patient tumour biopsies RNA was isolated using an Allin-One purification kit (Norgen Biotek). Aurum Total RNA Mini Kit (Biorad, UK) was used for RNA extraction from cell lines.

For miRNA expression analysis, 10 ng total RNA was first reverse transcribed to cDNA using the TaqMan MicroRNA Reverse Transcription Kit (Applied Biosystems, UK). TaqMan microRNA assays and TaqMan 2X Universal PCR Master Mix (Applied Biosystems, UK) were used, with RNU48 used as the endogenous control. For mRNA analysis, $1 \mu \mathrm{g}$ total RNA was reversed transcribed using the RevertAid H Minus First Strand CDNA Synthesis Kit (Thermo Scientific, UK). QuantiNova SYBR Green PCR Kit and QuantiTECT primer assays (Qiagen, UK) were used, with $B 2 M$ or $18 S$ used as the endogenous control. RT-qPCR was performed using the Step One Plus Real Time PCR System (Applied Bioscience, USA) and data was analysed using the $2^{-\Delta \Delta \mathrm{Ct}}$ method (28). Primer details available in Supplementary Table 1.

\section{Clonogenic assay}

Cells were plated at a density of 500-5000 cells/well in 6-well plastic plates. Colonies were fixed and stained by crystal violet staining solution $(0.1 \% \mathrm{w} / \mathrm{v}$ crystal violet, $70 \% \mathrm{v} / \mathrm{v}$ methanol, $30 \% \mathrm{v} / \mathrm{v} \mathrm{dH_{2 }}$ O) after 7-10 days post treatment. Colonies were counted using a Gel Count system (Oxford Optronics, UK). 
Running title: PI3K signalling as a therapeutic target in radioresistant OAC

\section{Cell viability assay}

Short term cell viability was assessed using the Cell Titer 96 AQeous One Solution MTS cell proliferation assay (Promega, UK), as previously described \{Beeby, 2020 \#46\}.

\section{Immunoblotting}

Cells lysates were prepared in UTB as previously reported (29). Tumour samples were prepared for lysis using a BioPulverizer and Cryo-cup grinder (BioSpec, USA) and lysed in RIPA buffer (Cell Signalling Technology, USA) supplemented with protease (Mini, EDTA-free Protease Inhibitor Cocktail, Roche, UK) and phosphatase (PhosSTOP, Roche, UK) inhibitors. Western blotting was performed as previously described (29). Densitometric analysis of band intensity of blots was carried out using Image J (NIH, USA).

\section{Statistical analysis}

Statistical analysis was carried out using the GraphPad PRISM (GraphPad software Inc, California, USA) and the data presented represent the mean $+/-$ the standard error of the mean (SEM). Statistical analysis was carried out using an unpaired Student's T-test or a 2-way ANOVA. Significance was assumed if $p<0.05$.

Detailed materials and methods are described in the Supplementary Materials. 
Running title: PI3K signalling as a therapeutic target in radioresistant OAC

\section{Results}

\section{PTEN expression is associated with CRT response in OAC patients}

We have previously shown that miR-187 is downregulated in poor responder patients in OAC and can impact on gene expression for survival pathways (10). Here, we confirmed that miR187 overexpression resulted in significant upregulation of PTEN mRNA expression in a OAC cell line panel compared to non-transfected controls (Figure 1A, Supplementary Figure 1A), linking miR-187 levels with PTEN expression. As a search of the miR-code database (30) did not reveal a miR-187 binding site in the PTEN promotor, PTEN regulatory co-factors were identified using the UCSC genome browser, and those with miR-187 seed sites identified using the miR-code database (Supplementary Table 3). For the most promising negative regulators EP300 or DNMT1, expression was not affected by miR-187 overexpression, while KDMB5 expression was significantly increased in the OE33 and SK-GT-4 cell lines (Supplementary Figure 2), indicating that other factors must be responsible for miR-187mediated PTEN modulation. The effect of miR-187 overexpression on downstream PI3K-AKT signalling was then assessed through analysis of phosphorylated AKT levels (Serine 473). MiR187 overexpression resulted in significant reduction of pAKT levels compared to the nontransfected controls (Figure 1B, Supplementary Figure 3). Finally, we observed PTEN expression was significantly downregulated in the pre-treatment tumour biopsies of poor responders to neo-CRT compared to the responder group (Figure 1C). These data suggest that PTEN/PI3K-AKT signalling correlates with miR-187 expression in vitro and is associated with radiation response efficacy in OAC patients. 
bioRxiv preprint doi: https://doi.org/10.1101/2020.10.23.351981; this version posted October 23, 2020. The copyright holder for this preprint (which was not certified by peer review) is the author/funder. All rights reserved. No reuse allowed without permission.

Running title: PI3K signalling as a therapeutic target in radioresistant OAC

\section{PI3K inhibition efficiently reduces OAC cell survival in vitro and in vivo tumour growth}

We hypothesised that pharmacological inhibition of PI3K may provide an alternative novel therapeutic strategy for OAC in patients with repressed miR-187 expression who do not respond to neo-CRT. Clinically relevant PI3K inhibitor GDC-0941 was selected for further investigation due to the high efficacy shown in pre-clinical studies and phase I clinical trials for solid tumours $(13-15,25,26,31)$. GDC-0941 treatment resulted in PI3K inhibition as indicated via a reduction (lower doses) or abrogation (higher doses) in phospho-AKT in the OAC cell line panel (Figure 2A). Treatment with GDC-0941 significantly reduced both shortterm viability(Figure 2B) and long-term clonogenic survival (Figure $2 \mathrm{C}$ ) for the OAC cell line panel. These data confirm that GDC-0941 effectively reduces cell survival as a single agent in vitro.

Pre-clinical efficacy was then assessed in vivo using OE33 tumour xenograft models. Significant reduction in tumour growth was observed in mice treated with GDC-0941 (50 $\mathrm{mg} / \mathrm{kg}$ ) compared to those treated with the vehicle control (Figure $3 \mathrm{~A}$ ). pAKT levels were reduced in the GDC-0941 treated group compared to those treated with the vehicle control, indicating that PI3K signalling was successfully inhibited (Figure 3B). This is the first pre-clinical study to evaluate its efficacy for the treatment of OAC.

\section{PI3K inhibition enhances radiosensitivity in OAC in vitro}

Treatment with GDC-0941 significantly reduced long term clonogenic survival of OAC cell lines both as a single agent and in combination with irradiation as compared to the vehicle control, through an additive effect (Figure 4A, Supplementary Figure 4). Finally, treatment of all three OAC cell lines with GDC-0941 significantly reduced OAC spheroid volume, which was exacerbated in combination with ionising radiation (Figure 4B-D). These data suggest that 
bioRxiv preprint doi: https://doi.org/10.1101/2020.10.23.351981; this version posted October 23,2020 . The copyright holder for this preprint (which was not certified by peer review) is the author/funder. All rights reserved. No reuse allowed without permission.

Running title: PI3K signalling as a therapeutic target in radioresistant OAC

PI3K inhibition through treatment with GDC-0941 significantly reduces the long-term clonogenic survival of OAC cell lines as a single agent and in combination with physiologically relevant levels of ionising radiation.

\section{Discussion}

In the present study, miR-187 overexpression was shown to induce upregulation of the tumour suppressor gene PTEN which resulted in subsequent inhibition of downstream PI3KAKT signalling in OAC cell lines. PTEN expression levels were also found to be significantly downregulated in the pre-treatment biopsy specimens of OAC patients displaying a poor response to neo-CRT (Figure 1). Our findings are supported by the findings of Saeed and colleagues, where AKT expression levels were increased in the pre-treatment tumour biopsies of OAC patients identified as partial or non-responders to neo-CRT compared to those with a pCR. AKT expression was also shown to significantly correlate to the degree of pathologic response (32). As PTEN is a well-established negative regulator of the PI3K-AKT signalling pathway, our current and previous findings, alongside those published by Saeed and colleagues (32), indicate that miR-187, PTEN, and downstream PI3K-AKT signalling are implicated in modulating neo-CRT response in OAC. This suggests that decreased PTEN expression could be predictive of OAC radioresistance, as it is well established that the PI3KAKT signalling pathway becomes upregulated in response to radiotherapy and is implicated in radiation resistance (33). Therefore, manipulation of PI3K may provide alternative therapeutic strategies for tackling radiation resistance in OAC. 
bioRxiv preprint doi: https://doi.org/10.1101/2020.10.23.351981; this version posted October 23, 2020. The copyright holder for this preprint (which was not certified by peer review) is the author/funder. All rights reserved. No reuse allowed without permission.

Running title: PI3K signalling as a therapeutic target in radioresistant OAC

We hypothesised that a negative PTEN transcriptional regulator harbouring a miR-187 binding site is responsible for miR-187 modulation of PTEN in OAC, as PTEN does not appear to be a direct target for miR-187. Unfortunately, candidate regulators EP300, KDM5B and DMNT1 were also not affected by miR-187 overexpression (Supplementary Figure 2), indicating that other intermediate factors might be involved. Of particular interest from our in silico analysis (Supplementary Table 3), both NFIC (Nuclear Factor I C) and PHF8 (PHD Finger Protein 8) were identified as potential miR-187 targets with an impact on PTEN expression through a yet unknown regulation mechanism, and have been shown to be overexpressed in oesophageal squamous cell carcinoma $(34,35)$, which will be evaluated in future studies.

Inhibition of PI3K signalling using the clinically relevant agent GDC-0941 significantly decreased cellular survival and enhanced radiation response in 2D and 3D models in vitro, as well as leading to tumour growth inhibition as a single agent in OAC xenograft models (Figures 2-4). The data presented here support previous studies which demonstrated that OAC and OSCC cell lines are sensitive to the previous generation PI3K inhibitors Wortmannin and LY294002 (36-38). Unlike the previous generation PI3K inhibitors, the PI3K inhibitor GDC-0941 used in this study is a highly selective inhibitor that targets all four isoforms of class I PI3Ks, the effects of which have not previously been assessed in oesophageal cancer (13). Importantly, this is the first study to demonstrate the efficacy of GDC-0941 for the treatment of OAC, either as a single agent or in combination with radiotherapy. These findings support those of previous pre-clinical studies and clinical trials indicating that GDC-0941 is suitable for the treatment of solid tumours $(13,15,16)$. PI3K inhibition has been shown to modulate radio-sensitivity in a range of malignancies including lung, prostate and thyroid carcinoma $(39,40)$, although this is the first study evaluating the effect of PI3K inhibition on radio- 
Running title: $\mathrm{PI} 3 \mathrm{~K}$ signalling as a therapeutic target in radioresistant OAC

sensitivity in OAC. Our study indicates, for the first time, that PI3K inhibition may enhance radiotherapy response in OAC.

\section{Conclusions}

We have shown that PTEN and PI3K signalling are implicated in modulating tumour response to neo-CRT in OAC patients. We have also demonstrated that the clinically relevant PI3K inhibitor GDC-0941 significantly decreased cellular survival and enhanced the efficacy of radiation treatment in OAC cell lines in vitro, as well as leading to inhibiting tumour growth as a single agent in in vivo xenograft models. Importantly, the preliminary data presented here demonstrate that PI3K inhibitors such as GDC-0941 may provide an alternative therapeutic strategy for the treatment of OAC, either as a single agent or in combination with neo-CRT. 
bioRxiv preprint doi: https://doi.org/10.1101/2020.10.23.351981; this version posted October 23, 2020. The copyright holder for this preprint (which was not certified by peer review) is the author/funder. All rights reserved. No reuse allowed without permission.

Running title: PI3K signalling as a therapeutic target in radioresistant OAC

\section{References}

1. Bray F, Ferlay J, Soerjomataram I, Siegel RL, Torre LA, Jemal A. Global cancer statistics 2018: GLOBOCAN estimates of incidence and mortality worldwide for 36 cancers in 185 countries. CA Cancer J Clin. 2018;68(6):394-424.

2. Arnold M, Soerjomataram I, Ferlay J, Forman D. Global incidence of oesophageal cancer by histological subtype in 2012. Gut. 2015;64(3):381-7.

3. Arnold M, Laversanne M, Brown LM, Devesa SS, Bray F. Predicting the Future Burden of Esophageal Cancer by Histological Subtype: International Trends in Incidence up to 2030. Am J Gastroenterol. 2017;112(8):1247-55.

4. Rashid N, Elshaer M, Kosmin M, Riaz A. Current management of oesophageal cancer. BJMP. 2015;8(1):a804.

5. Reynolds JV, Muldoon C, Hollywood D, Ravi N, Rowley S, O'Byrne K, et al. Long-term outcomes following neoadjuvant chemoradiotherapy for esophageal cancer. Ann Surg. 2007;245(5):707-16.

6. van Hagen $\mathrm{P}$, Hulshof $\mathrm{MC}$, van Lanschot JJ, Steyerberg EW, van Berge Henegouwen MI, Wijnhoven BP, et al. Preoperative chemoradiotherapy for esophageal or junctional cancer. N Engl J Med. 2012;366(22):2074-84.

7. Skinner HD, Lee JH, Bhutani MS, Weston B, Hofstetter W, Komaki R, et al. A validated miRNA profile predicts response to therapy in esophageal adenocarcinoma. Cancer. 2014;120(23):3635-41.

8. Bibby BA, Reynolds JV, Maher SG. MicroRNA-330-5p as a Putative Modulator of Neoadjuvant Chemoradiotherapy Sensitivity in Oesophageal Adenocarcinoma. PLoS One. 2015;10(7):e0134180.

9. Lynam-Lennon N, Reynolds JV, Marignol L, Sheils OM, Pidgeon GP, Maher SG. MicroRNA-31 modulates tumour sensitivity to radiation in oesophageal adenocarcinoma. J Mol Med (Berl). 2012;90(12):1449-58.

10. Lynam-Lennon N, Bibby BA, Mongan AM, Marignol L, Paxton CN, Geiersbach K, et al. Low miR187 expression promotes resistance to chemoradiation therapy in vitro and correlates with treatment failure in patients with esophageal adenocarcinoma. Mol Med. 2016;22.

11. Stambolic V, Suzuki A, de la Pompa JL, Brothers GM, Mirtsos C, Sasaki T, et al. Negative regulation of PKB/Akt-dependent cell survival by the tumor suppressor PTEN. Cell. 1998;95(1):29-39.

12. Kebenko M, Drenckhan A, Gros SJ, Jucker M, Grabinski N, Ewald F, et al. ErbB2 signaling activates the Hedgehog pathway via PI3K-Akt in human esophageal adenocarcinoma: identification of novel targets for concerted therapy concepts. Cell Signal. 2015;27(2):373-81.

13. Raynaud FI, Eccles SA, Patel S, Alix S, Box G, Chuckowree I, et al. Biological properties of potent inhibitors of class I phosphatidylinositide 3-kinases: from PI-103 through PI-540, PI-620 to the oral agent GDC-0941. Mol Cancer Ther. 2009;8(7):1725-38.

14. Burrows N, Babur M, Resch J, Ridsdale S, Mejin M, Rowling EJ, et al. GDC-0941 inhibits metastatic characteristics of thyroid carcinomas by targeting both the phosphoinositide-3 kinase (PI3K) and hypoxia-inducible factor-1alpha (HIF-1alpha) pathways. J Clin Endocrinol Metab. 2011;96(12):E1934-43.

15. Sarker D, Ang JE, Baird R, Kristeleit R, Shah K, Moreno V, et al. First-in-human phase I study of pictilisib (GDC-0941), a potent pan-class I phosphatidylinositol-3-kinase (PI3K) inhibitor, in patients with advanced solid tumors. Clin Cancer Res. 2015;21(1):77-86.

16. Schoffski P, Cresta S, Mayer IA, Wildiers H, Damian S, Gendreau S, et al. A phase Ib study of pictilisib (GDC-0941) in combination with paclitaxel, with and without bevacizumab or trastuzumab, and with letrozole in advanced breast cancer. Breast Cancer Res. 2018;20(1):109.

17. Shi F, Guo H, Zhang R, Liu H, Wu L, Wu Q, et al. The PI3K inhibitor GDC-0941 enhances radiosensitization and reduces chemoresistance to temozolomide in GBM cell lines. Neuroscience. 2017;346:298-308. 
bioRxiv preprint doi: https://doi.org/10.1101/2020.10.23.351981; this version posted October 23, 2020. The copyright holder for this preprint (which was not certified by peer review) is the author/funder. All rights reserved. No reuse allowed without permission.

Running title: PI3K signalling as a therapeutic target in radioresistant OAC

18. Burrows N, Williams J, Telfer BA, Resch J, Valentine HR, Fitzmaurice RJ, et al. Phosphatidylinositide 3-kinase (PI3K) and PI3K-related kinase (PIKK) activity contributes to radioresistance in thyroid carcinomas. Oncotarget. 2016;7(39):63106-23.

19. Pires IM, Olcina MM, Anbalagan S, Pollard JR, Reaper PM, Charlton PA, et al. Targeting radiation-resistant hypoxic tumour cells through ATR inhibition. Br J Cancer. 2012;107(2):291-9.

20. Beeby E, Magalhaes M, Pocas J, Collins T, Lemos MFL, Barros L, et al. Secondary metabolites (essential oils) from sand-dune plants induce cytotoxic effects in cancer cells. J Ethnopharmacol. 2020;258:112803.

21. Moore CS, Wood TJ, Cawthorne C, Hilton KL, Maher S, Saunderson JR, et al. A method to calibrate the RS $2000 \mathrm{x}$-ray biological irradiator for radiobiological flank irradiation of mice. Biomedical Physics \& Engineering Express. 2016;2(3).

22. Maher SG, Gillham CM, Duggan SP, Smyth PC, Miller N, Muldoon C, et al. Gene expression analysis of diagnostic biopsies predicts pathological response to neoadjuvant chemoradiotherapy of esophageal cancer. Ann Surg. 2009;250(5):729-37.

23. Mandard AM, Dalibard F, Mandard JC, Marnay J, Henry-Amar M, Petiot JF, et al. Pathologic assessment of tumor regression after preoperative chemoradiotherapy of esophageal carcinoma. Clinicopathologic correlations. Cancer. 1994;73(11):2680-6.

24. Fridman R, Benton G, Aranoutova I, Kleinman HK, Bonfil RD. Increased initiation and growth of tumor cell lines, cancer stem cells and biopsy material in mice using basement membrane matrix protein (Cultrex or Matrigel) co-injection. Nat Protoc. 2012;7(6):1138-44.

25. Burrows N, Telfer B, Brabant G, Williams KJ. Inhibiting the phosphatidylinositide 3-kinase pathway blocks radiation-induced metastasis associated with Rho-GTPase and Hypoxia-inducible factor-1 activity. Radiother Oncol. 2013;108(3):548-53.

26. Cawthorne C, Burrows N, Gieling RG, Morrow CJ, Forster D, Gregory J, et al. [18F]-FLT positron emission tomography can be used to image the response of sensitive tumors to PI3-kinase inhibition with the novel agent GDC-0941. Mol Cancer Ther. 2013;12(5):819-28.

27. Faul F, Erdfelder E, Lang AG, Buchner A. G*Power 3: a flexible statistical power analysis program for the social, behavioral, and biomedical sciences. Behav Res Methods. 2007;39(2):175-91.

28. Livak KJ, Schmittgen TD. Analysis of relative gene expression data using real-time quantitative PCR and the 2(-Delta Delta C(T)) Method. Methods. 2001;25(4):402-8.

29. Poujade FA, Mannion A, Brittain N, Theodosi A, Beeby E, Leszczynska KB, et al. WSB-1 regulates the metastatic potential of hormone receptor negative breast cancer. $\mathrm{Br} \mathrm{J}$ Cancer. 2018;118(9):1229-37.

30. Jeggari A, Marks DS, Larsson E. miRcode: a map of putative microRNA target sites in the long non-coding transcriptome. Bioinformatics. 2012;28(15):2062-3.

31. O'Brien C, Wallin JJ, Sampath D, GuhaThakurta D, Savage H, Punnoose EA, et al. Predictive biomarkers of sensitivity to the phosphatidylinositol 3' kinase inhibitor GDC-0941 in breast cancer preclinical models. Clin Cancer Res. 2010;16(14):3670-83.

32. Saeed N, Shridhar R, Hoffe S, Almhanna K, Meredith KL. AKT expression is associated with degree of pathologic response in adenocarcinoma of the esophagus treated with neoadjuvant therapy. J Gastrointest Oncol. 2016;7(2):158-65.

33. Burris HA. Overcoming acquired resistance to anticancer therapy: focus on the PI3K/AKT/mTOR pathway. Cancer chemotherapy and pharmacology. 2013;71(4):829-42.

34. Wang H, Shi X, Wu S. miR-550a-3/NFIC plays a driving role in esophageal squamous cell cancer cells proliferation and metastasis partly through EMT process. Mol Cell Biochem. 2020;472(1-2):11523.

35. Sun X, Qiu JJ, Zhu S, Cao B, Sun L, Li S, et al. Oncogenic features of PHF8 histone demethylase in esophageal squamous cell carcinoma. PLoS One. 2013;8(10):e77353.

36. Li B, Cheung PY, Wang X, Tsao SW, Ling MT, Wong YC, et al. Id-1 activation of $\mathrm{PI} I \mathrm{~K} / \mathrm{Akt} / \mathrm{NFkappaB}$ signaling pathway and its significance in promoting survival of esophageal cancer cells. Carcinogenesis. 2007;28(11):2313-20. 
bioRxiv preprint doi: https://doi.org/10.1101/2020.10.23.351981; this version posted October 23, 2020. The copyright holder for this preprint (which was not certified by peer review) is the author/funder. All rights reserved. No reuse allowed without permission.

Running title: PI3K signalling as a therapeutic target in radioresistant OAC

37. Li B, Tsao SW, Li YY, Wang X, Ling MT, Wong YC, et al. Id-1 promotes tumorigenicity and metastasis of human esophageal cancer cells through activation of PI3K/AKT signaling pathway. Int J Cancer. 2009;125(11):2576-85.

38. Pal J, Fulciniti M, Nanjappa P, Buon L, Tai YT, Tassone $P$, et al. Targeting PI3K and RAD51 in Barrett's adenocarcinoma: impact on DNA damage checkpoints, expression profile and tumor growth. Cancer Genomics Proteomics. 2012;9(2):55-66.

39. Schuurbiers OC, Kaanders JH, van der Heijden HF, Dekhuijzen RP, Oyen WJ, Bussink J. The PI3K/AKT-pathway and radiation resistance mechanisms in non-small cell lung cancer. J Thorac Oncol. 2009;4(6):761-7.

40. Chang L, Graham PH, Hao J, Ni J, Bucci J, Cozzi PJ, et al. PI3K/Akt/mTOR pathway inhibitors enhance radiosensitivity in radioresistant prostate cancer cells through inducing apoptosis, reducing autophagy, suppressing NHEJ and HR repair pathways. Cell Death Dis. 2014;5:e1437. 
$1 \mathrm{~A}$

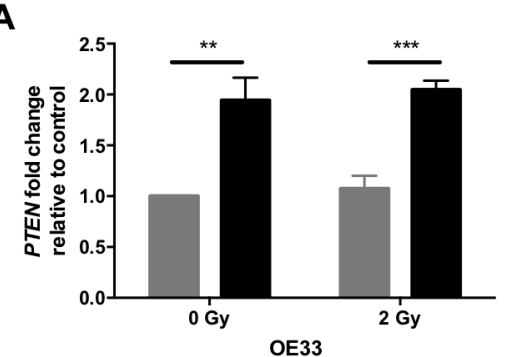

$1 B$

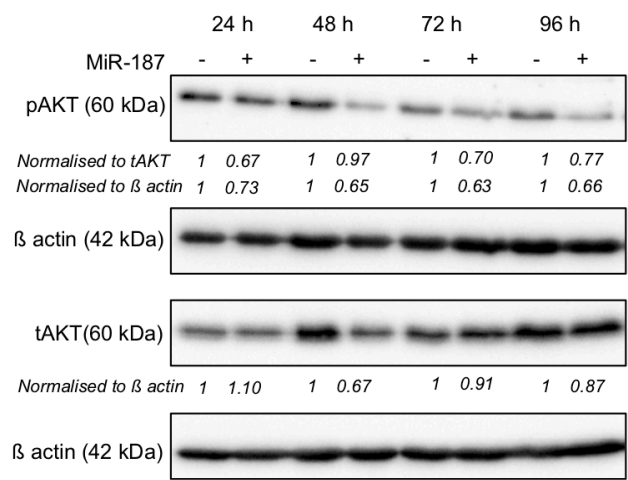

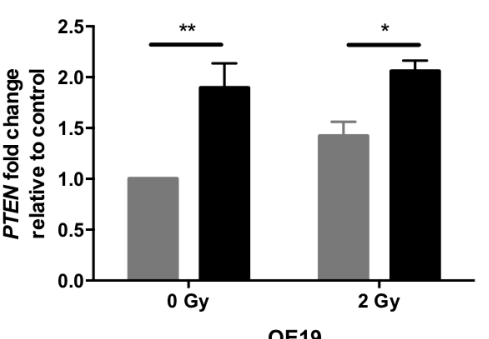

OE19

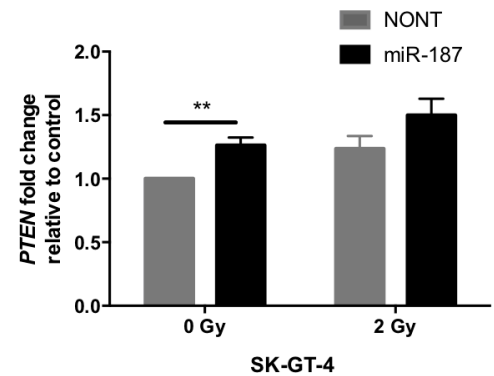

$1 \mathrm{C}$

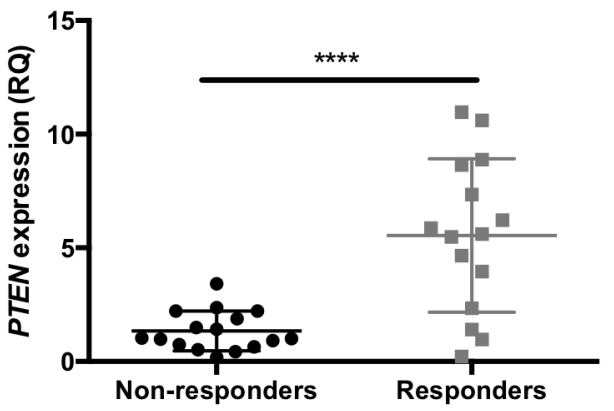

Figure 1 - PTEN expression is associated with CRT response in OAC patients.

A) OE33, OE19 and SK-GT-4 cells were transfected with pre-miR-187 precursor molecules and exposed to 2 Gy irradiation. PTEN fold change was analyzed by qPCR and expression calculated relative to the nontransfected control (NONT). Histogram represents an average of $n=3$ experimental repeats. B) OE33 cells were transfected with pre-miR-187 precursor molecules and tAKT/ pAKT protein levels assessed by western blot. Western blot and densitometry shown is representative of $n=3$ repeats. C) PTEN expression was assessed in the pre-treatment diagnostic biopsy specimens of OAC patients $(n=31)$ by qPCR. Patients were classified as neo-CRT responders (TRG 1 and 2, $n=15$ ) and non-responders (TRG 4 and 5, n=16). Error bars represent mean \pm SEM. ${ }^{*} p<0.05,{ }^{* *} p<0.01,{ }^{* * *} p<0.001, * * * * p<0.0001$. 
2A

OE33

OE19

SK-GT-4

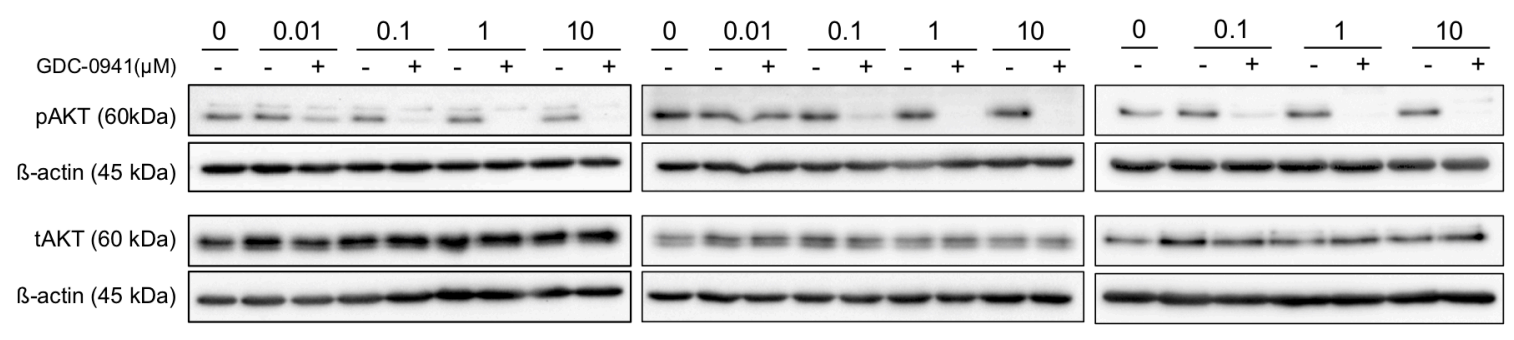

2B
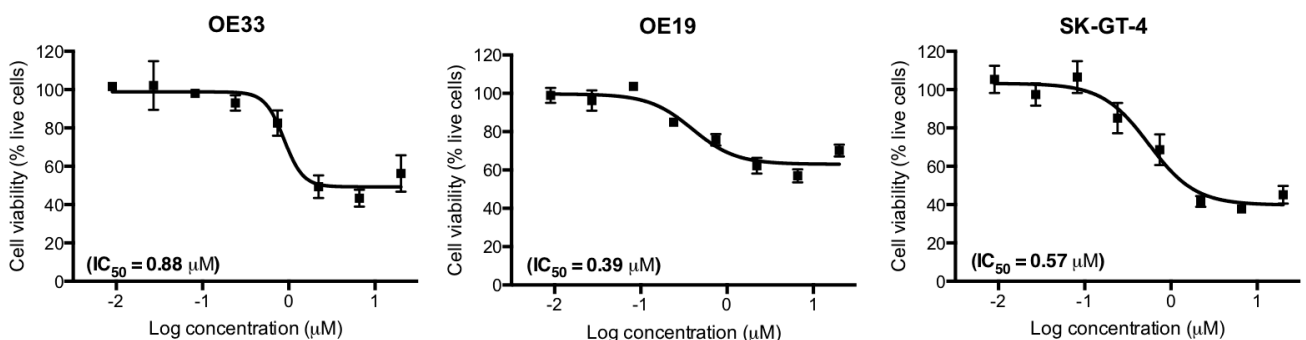

2C
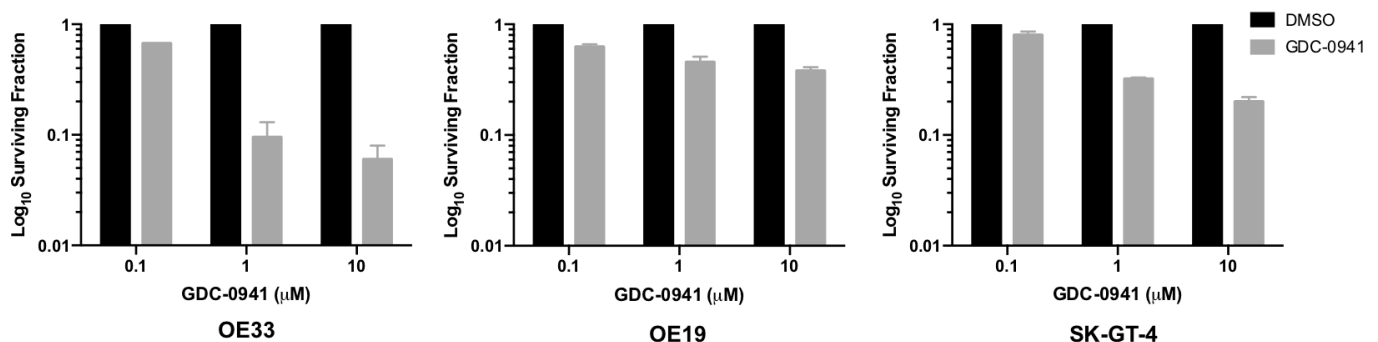

Figure 2 - PI3K inhibition significantly reduces OAC proliferation and survival in vitro.

A) Cells were treated with GDC-0941 or vehicle control for $18 \mathrm{~h}$ and tAKT/ PAKT (Ser 473) protein levels assessed by western blot. Western blot is representative of $n=3$ repeats. B) Cells were treated with GDC0941 at a top concentration of $20 \mu \mathrm{M}$ and an 8-point dose response curve generated. The MTS reagent was added to the plates $48 \mathrm{~h}$ post treatment and absorbance measured at $490 \mathrm{~nm} 4 \mathrm{~h}$ later. Cell viability was calculated relative to the corresponding vehicle control for each dose $(n=3)$. C) Cells were treated with GDC-0941 or vehicle control and the effect on long term survival assessed using the clonogenic assay. Data represent the average of $n=2$ experimental repeats. Error bars represent mean \pm SEM. 


\section{A}

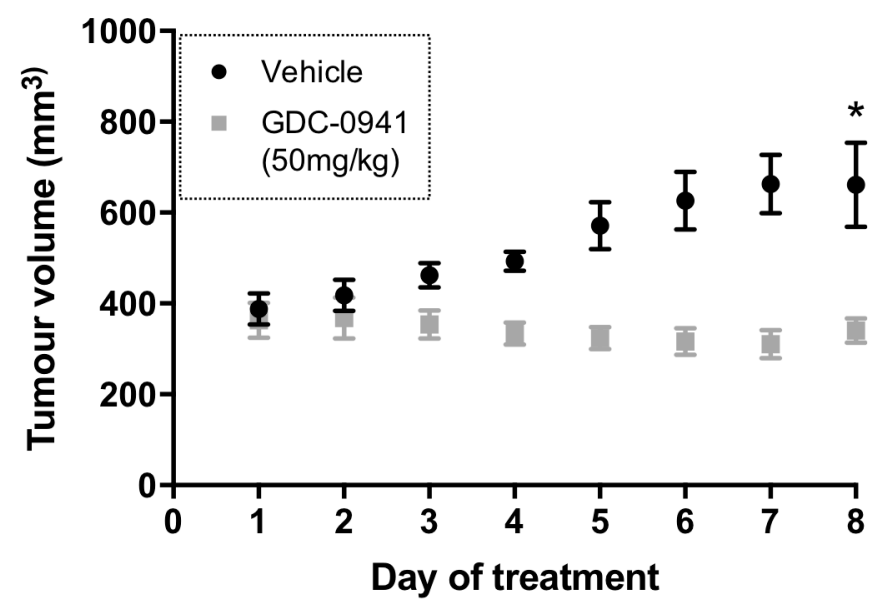

\section{B}

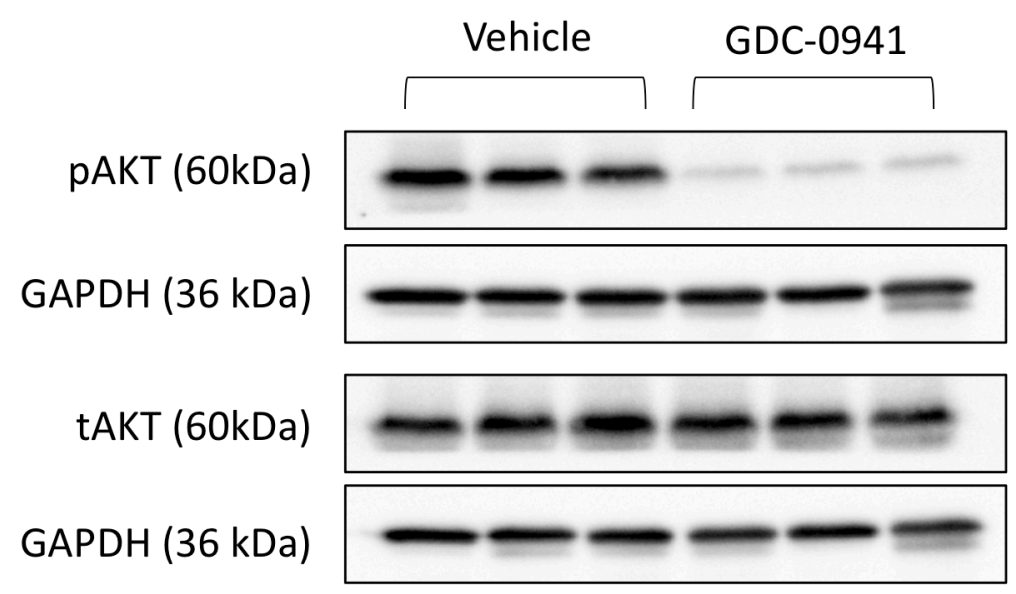

Figure 3 - GDC-0941 treatment significantly decreases OAC tumour growth in vivo.

A) SCID-Beige female mice bearing OE33 tumour xenografts were treated twice daily with GDC-0941 (50 $\mathrm{mg} / \mathrm{kg}$ ) or vehicle control via oral gavage for 8 days. Data represents the average mean tumour volume of $n=3$ (treated) or $n=3$ (vehicle) animals per treatment group. B) Animals were sacrificed 1 hour after the final treatment dose and tAKT/ PAKT protein levels assessed by western blot. Western blot is representative of $n=3$ repeats. Error bars represent mean \pm SEM. ${ }^{*} p<0.05$ 
4A

口 DMSO 0Gy $\mathbb{Z}$ DMSO2Gy

口GDC-09410Gy 西 GDC-09412Gy

OE33
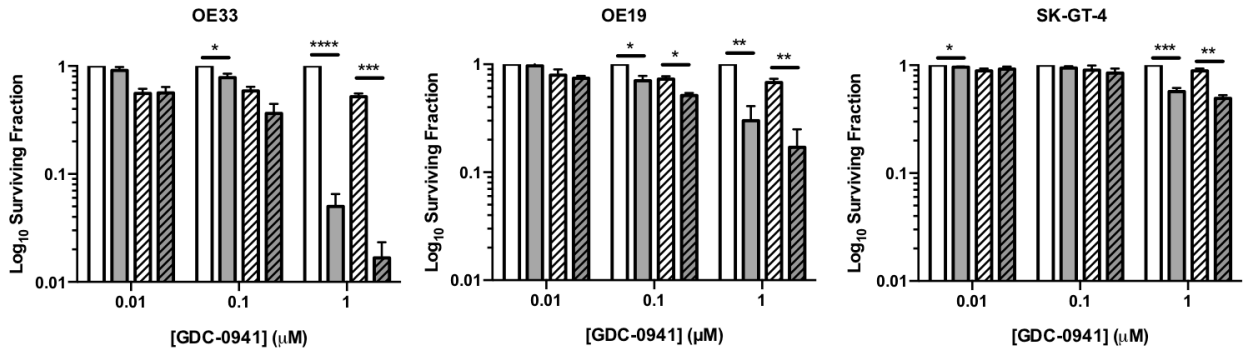

$4 B$
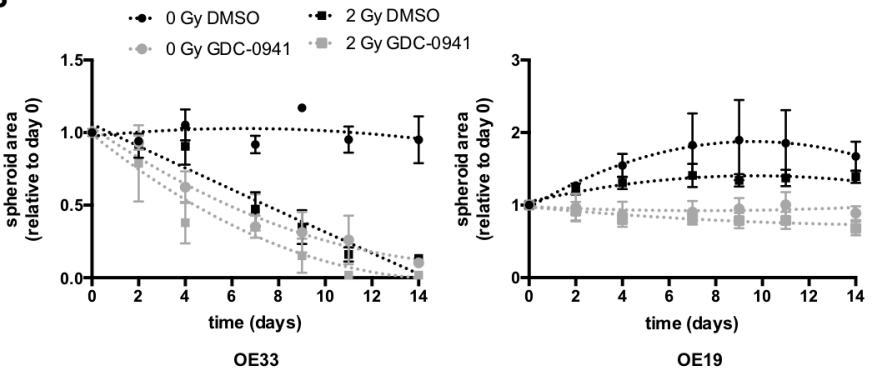

$4 \mathrm{C}$

Day 11

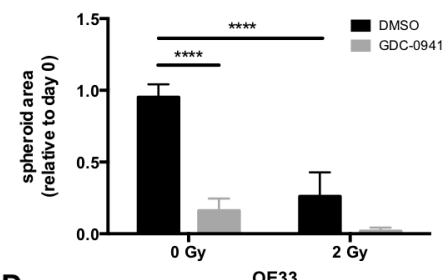

4D
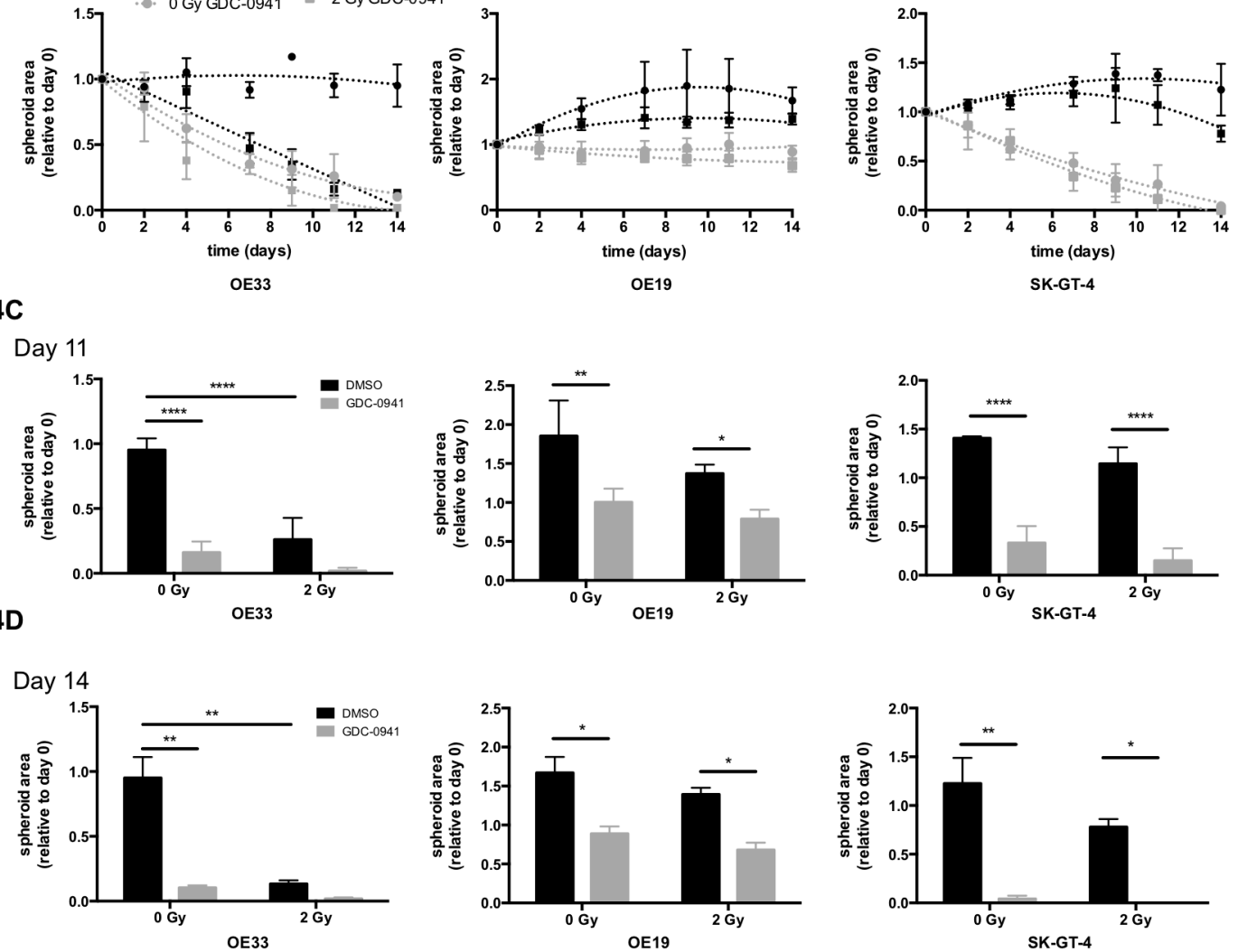

33

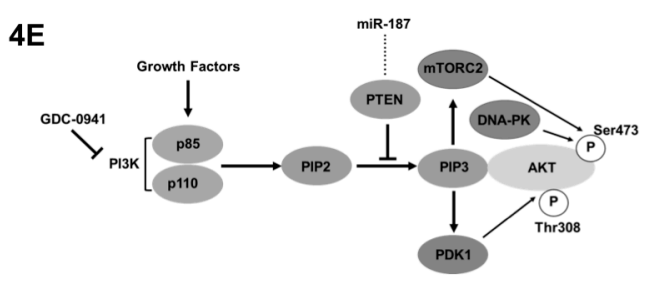

Figure 4 - PI3K inhibition enhances radiotherapy treatment in 2D and 3D OAC models.

A) Cells were treated with GDC-0941 or vehicle control for 18 hours and exposed to 2 Gy irradiation. The effect of GDC-0941 as a single agent and in combination with 2 Gy irradiation was assessed using the clonogenic assay. The surviving fraction was calculated relative to the 0 Gy DMSO control. B-D) OE33, OE19, and SK-GT-4 spheroids were treated with 1 MM GDC-0941 or DMSO for 21 days in combination with a total of $5 \times 2 \mathrm{~Gy}$ irradiation fractions or mock irradiated for the first 5 days. Spheroids were imaged using the GelCount instrument (Oxford Optronix), and spheroid size determined using ImageJ (NIH). Spheroid area is shown relative to day 0 . Error bars represent mean \pm SEM. ${ }^{*} p<0.05,{ }^{* *} p<0.01,{ }^{* * *} p<0.001$, $* * * * p<0.0001$. E) Schematic of the effect of GDC-0941 treatment of the PI3K-AKT signalling pathway. 